\title{
Differential Impact of Inhibitory G-Protein Signaling Pathways in Ventral Tegmental Area Dopamine Neurons on Behavioral Sensitivity to Cocaine and Morphine
}

\author{
Margot C. DeBaker, ${ }^{1}$ EEzequiel Marron Fernandez de Velasco, ${ }^{2}$ Nora M. McCall, ${ }^{1}$ Anna M. Lee, ${ }^{2}$ and \\ (- Kevin Wickman ${ }^{2}$
}

https://doi.org/10.1523/ENEURO.0081-21.2021

${ }^{1}$ Graduate Program in Neuroscience, University of Minnesota, Minneapolis, MN 55455 and ${ }^{2}$ Department of Pharmacology, University of Minnesota, Minneapolis, MN 55455

\begin{abstract}
Drugs of abuse engage overlapping but distinct molecular and cellular mechanisms to enhance dopamine (DA) signaling in the mesocorticolimbic circuitry. DA neurons of the ventral tegmental area (NTA) are key substrates of drugs of abuse and have been implicated in addiction-related behaviors. Enhanced VTA DA neurotransmission evoked by drugs of abuse can engage inhibitory G-protein-dependent feedback pathways, mediated by $G A B A_{B}$ receptors $\left(G A B A_{B} R s\right)$ and $D_{2}$ DA receptors $\left(D_{2} R s\right)$. Chemogenetic inhibition of VTA DA neurons potently suppressed baseline motor activity, as well as the motor-stimulatory effect of cocaine and morphine, confirming the critical influence of VTA DA neurons and inhibitory G-protein signaling in these neurons on this addiction-related behavior. To resolve the relative influence of $G A B A_{B} R$-dependent and $D_{2} R$-dependent signaling pathways in VTA DA neurons on behavioral sensitivity to drugs of abuse, we developed a neuron-specific viral CRISPR/Cas 9 approach to ablate $D_{2} R$ and $\mathrm{GABA}_{B} \mathrm{R}$ in VTA DA neurons. Ablation of $G A B A_{B} R$ or $D_{2} R$ did not impact baseline physiological properties or excitability of VTA DA neurons, but it did preclude the direct somatodendritic inhibitory influence of $G A B A_{B} R$ or $D_{2} R$ activation. $D_{2} R$ ablation potentiated the motor-stimulatory effect of cocaine in male and female mice, whereas $G A B A_{B} R$ ablation selectively potentiated cocaine-induced activity in male subjects only. Neither $D_{2} R$ nor $G A B A_{B} R$ ablation impacted morphine-induced motor activity. Collectively, our data show that cocaine and morphine differ in the extent to which they engage inhibitory G-protein-dependent feedback pathways in VTA DA neurons and highlight key sex differences that may impact susceptibility to various facets of addiction.
\end{abstract}

Key words: cocaine; CRISPR; D2 dopamine receptor; GABA ${ }_{B}$ receptor; morphine; sex differences

\section{Significance Statement}

Although inhibitory G-protein-dependent signaling involving the $G A B A_{B}$ receptor $\left(G A B A_{B} R\right)$ and $D_{2}$ dopamine (DA) receptor $\left(D_{2} R\right)$ in ventral tegmental area (VTA) DA neurons is thought to limit DA neurotransmission evoked by drugs of abuse, their relative impact on behavioral sensitivity to such drugs is unclear. Using a neuron-specific viral CRISPR/Cas9 approach, we show that loss of $D_{2} R$ in VTA DA neurons enhances behavioral sensitivity to systemic administration of cocaine in male and female mice, whereas loss of $G A B A_{B} R$ enhances cocaine sensitivity only in males. Neither $G A B A_{B} R$ nor $D_{2} R$ ablation impacted behavioral sensitivity to morphine. Thus, differential engagement of inhibitory feedback pathways in VTA DA neurons likely contributes to drug-specific neurophysiological and behavioral effects and may underlie sex differences associated with some facets of addiction.

Received March 2, 2021; accepted March 3, 2021; First published March 10, 2021.

The authors declare no competing financial interests.
Author contributions: K.W., M.C.D., E.M.F.d.V., N.M.M., and A.M.L. designed research; M.C.D. and N.M.M. performed research; E.M.F.d.V. contributed unpublished reagents/analytic tools; M.C.D. and N.M.M. analyzed data; K.W., M.C.D., and A.M.L. wrote the paper. 


\section{Introduction}

Dopamine (DA) neurons of the ventral tegmental area (VTA) are an integral part of the mesocorticolimbic system, a network of brain regions that mediates responses to natural rewards and drugs of abuse (Lammel et al., 2014; Volkow and Morales, 2015; Juarez and Han, 2016; Lüscher, 2016; Schultz, 2016). Drugs of abuse enhance DA neurotransmission in the mesocorticolimbic system via actions on distinct molecular targets (Di Chiara and Imperato, 1988; Lüscher and Ungless, 2006). Cocaine, for example, inhibits monoamine transporters, including the DA transporter (DAT), which recycles DA from the extracellular space, allowing DA levels to rise and persist in the VTA and its projection targets (Groves et al., 1975; Beart et al., 1979; Di Chiara and Imperato, 1988; Chen et al., 1996; Iravani et al., 1996; Adell and Artigas, 2004; Kita et al., 2009; Adrover et al., 2014). In contrast, morphine suppresses inhibitory GABAergic input, enhancing VTA DA neuron activity via disinhibition (Johnson and North, 1992; Jhou et al., 2009; Jalabert et al., 2011).

While enhanced DA neurotransmission underlies addiction-related behaviors (Hyman et al., 2006), it can also trigger negative feedback mediated by inhibitory G-protein signaling pathways (Steketee and Kalivas, 1990, 1991; Narayanan et al., 1996; Rahman and McBride, 2000). For example, cocaine elevates DA levels in the VTA and terminal regions, provoking feedback inhibition of VTA DA neurons via activation of $D_{2}$ DA receptors $\left(\mathrm{D}_{2} \mathrm{Rs}\right)$ in the somatodendritic compartment and axon terminals (Einhorn et al., 1988; Bradberry and Roth, 1989; Brodie and Dunwiddie, 1990; Beckstead et al., 2004; Ford, 2014). Cocaine also provokes GABAergic feedback to VTA DA neurons indirectly, by stimulating $D_{1} R$-expressing GABAergic medium spiny neurons in the nucleus accumbens (NAc) that project to the VTA (Rahman and McBride, 2001; Watabe-Uchida et al., 2012; Menegas et al., 2015; Edwards et al., 2017; Pignatelli and Bonci, 2018). This "long-loop" GABAergic feedback to VTA DA neurons is mediated primarily by activation of somatodendritic $G A B A_{B}$ receptors $\left(G A B A_{B} R s\right)$ on VTA DA neurons (Edwards et al., 2017).

Pharmacological and genetic approaches have implicated $G A B A_{B} R$ and $D_{2} R$-dependent signaling in the VTA in drug-induced behaviors. For example, pharmacological activation of $D_{2} R$ in the VTA suppressed cocaine-induced activity (Koulchitsky et al., 2016) and cocaine-reinstated

This work was supported by National Institutes of Health Grants DA034696 and AA027544 (to K.W.), DA007234 (to M.C.D.), DA041767 (to N.M.M.), AA026598 (to A.M.L.), and the University of Minnesota Viral Vector and Cloning Core (DA048742).

Acknowledgements: We thank Hannah Oberle, Mehrsa Zahiremami, and Courtney Wright for exceptional care of the mouse colony and the Genome Engineering and iPSC Center of Washington University for designing and validating gRNA sequences used in this study.

Correspondence should be addressed to Kevin Wickman at wickm002@ umn.edu.

https://doi.org/10.1523/ENEURO.0081-21.2021

Copyright (C) 2021 DeBaker et al.

This is an open-access article distributed under the terms of the Creative Commons Attribution 4.0 International license, which permits unrestricted use, distribution and reproduction in any medium provided that the original work is properly attributed. drug seeking behavior (Xue et al., 2011), while pharmacological inhibition of $D_{2} R$ in the VTA increased psychostimulant-induced locomotor activity (Chen and Reith, 1994; Tanabe et al., 2004). Similarly, intra-VTA infusion of the $\mathrm{GABA}_{\mathrm{B}} \mathrm{R}$ agonist baclofen blocked the locomotor-stimulatory effect of psychostimulants and opioids (Kalivas et al., 1990; Steketee and Kalivas, 1991; Chen and Reith, 1994; Leite-Morris et al., 2002, 2004) and attenuated selfadministration of cocaine, opioids, and other drugs of abuse (Xi and Stein, 1999; Brebner et al., 2000; LeiteMorris et al., 2004; Backes and Hemby, 2008). RNAimediated suppression of $D_{2} R$ in the rat VTA (cell non-selective) enhanced cocaine-related behavior (de Jong et al., 2015; Chen et al., 2018), enhanced choice impulsivity (Bernosky-Smith et al., 2018), and increased functional brain activity (Martin et al., 2020). Ablation of $D_{2} R$ in DA neurons throughout the mouse brain correlated with enhanced cocaine-induced activity (Bello et al., 2011), as well as acquisition of cocaine self-administration and reactivity to drug-paired cues (Holroyd et al., 2015). Interestingly, partial suppression of $\mathrm{GABA}_{B} R$ in VTA DA neurons unmasked cocaine-induced activity normally absent in BALB/c mice, but did not impact morphine-induced activity (Edwards et al., 2017).

Collectively, available data suggests that $D_{2} R$ and $\mathrm{GABA}_{\mathrm{B}} \mathrm{R}$-dependent signaling pathways in VTA DA neurons may exert a differential influence on behavioral sensitivity to drugs of abuse. Published studies investigating $D_{2} R$ and $G A B A_{B} R$ signaling in VTA DA neurons, however, have used approaches that provide either anatomic or cellular specificity, or do not completely suppress inhibitory signaling, or focus only on one signaling pathway or drug of abuse. Accordingly, the goal of this study was to compare the impact of $D_{2} R$ or $G A B A_{B} R$ ablation in VTA DA neurons on behavioral sensitivity to cocaine and morphine. To this end, we developed a neuron-specific viral CRISPR/Cas9 approach to ablate $D_{2} R$ and $G A B A_{B} R$ selectively in VTA DA neurons of adult mice. Our findings show that $D_{2} R$ and $G A B A_{B} R$-dependent signaling exert drug-specific and sex-specific influences on motor activity in mice.

\section{Materials and Methods}

\section{Animals}

All studies were approved by the Institutional Animal Care and Use Committee at the University of Minnesota. The B6.SJL-S/c6a3 ${ }^{t m 1.1(\mathrm{cre}) B \mathrm{kmn}} / \mathrm{J}$ (stock \#006660, The Jackson Laboratory) knock-in line was used in this study; heterozygous subjects, referred to throughout as DATCre $(+)$ mice, were generated by crossing with C57BL/6J subjects. DATCre(+) mice were also crossed in multiple rounds with a Cre-dependent Cas9GFP knock-in line

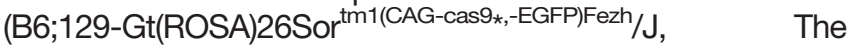
Jackson Laboratory, stock \#026179), to generate DATCre $(+)$ subjects homozygous for the Cas9GFP $(+)$ mutation; these mice are referred to throughout as DATCre $(+)$ :Cas9GFP $(+)$ mice. All mice used in experiments were bred in-house. Mice were group housed, maintained on a 14/10 h light/dark cycle and were provided ad libitum access to food and water. 


\section{Reagents}

Baclofen, quinpirole, and sulpiride were purchased from Sigma, and CGP54626 and clozapine-N-oxide (CNO) were purchased from Tocris. Cocaine and morphine were obtained through Boynton Health Pharmacy at the University of Minnesota. All adeno-associated viruses (AAVs) were packaged in AAV8 serotype by the University of Minnesota Viral Vector and Cloning Core (Minneapolis, MN) following standard packaging procedures (Chen et al., 2019), titers were between 0.2 and $4 \times 10^{14}$ genocopies $/ \mathrm{ml}$. The packaging plasmids (pRC8 and pHelper) were obtained from the University of Pennsylvania Vector Core. The plasmids pAAV-hSyn-hM4Di(mCherry) and pAAV-hSyn-DIO-mCherry (Addgene plasmids \#50475 and \#50459, respectively) were gifts from Bryan Roth. To obtain the pAAV-hSyn-DIO-hM4Di (mCherry) plasmid, the mCherry from the pAAV-hSyn-DIOmCherry was replaced by an hM4Di(mCherry) cassette via subcloning. For the CRISPR/Cas9 experiments the pAAVU6-gRNA-hSyn-NLSmCherry was generated using the backbone of the plasmid pAAV-U6-gRNA-hSyn-Cre-2AEGFP-KASH (Platt et al., 2014; Addgene plasmid \#60231) that was a gift from Feng Zhang. The Genome Engineering and iPSC Center of Washington University designed and tested guide RNA (gRNA) sequences targeting the Drd2 $\left(\mathrm{D}_{2} \mathrm{R}\right)$ and Gabbr1 $\left(\mathrm{GABA} \mathrm{A}_{\mathrm{B}} \mathrm{R} 1\right)$ genes. Sequences used were as follows: $D_{2} R$, CATGACAGTAACTCGGCGCT; GABA ${ }_{B} R 1$, ACGGCGTGCAGTATACATCG; LacZ, TGCGAATACGCC CACGCGAT.

\section{Intracranial manipulations}

Mice ( $>45$ d) were placed in a stereotaxic frame (David Kopf Instruments) under isoflurane anesthesia. Microinjectors, made by affixing a 33-gauge stainless steel hypodermic tube within a shorter 26-gauge stainless steel hypodermic tube, were attached to polyethylene-20 tubing affixed to $10-\mu$ l Hamilton syringes, and were lowered through burr holes in the skull to the VTA (from bregma: $-2.75 \mathrm{~mm} \mathrm{~A} / \mathrm{P}, \pm 0.55-0.7 \mathrm{~mm} \mathrm{M} / \mathrm{L},-5$ $\mathrm{mm} \mathrm{D/V);} 300-500 \mathrm{nl}$ of virus was injected per side at a rate of $100 \mathrm{nl} / \mathrm{min}$. The optimized coordinates and viral load ensured full coverage of the VTA along anterior/ posterior and rostral-caudal axes, with minimal spread into the adjacent substantia nigra pars compacta. Microinjectors were left in place for 10 min following infusion to reduce solution backflow along the infusion track. Slice electrophysiology and behavioral experiments were performed three to four and five to six weeks after viral infusion for chemogenetic and CRISPR experiments, respectively.

\section{Slice electrophysiology}

Electrophysiological properties of VTA DA neurons were evaluated in behaviorally naive adult mice (66-93 d). Horizontal slices $(225 \mu \mathrm{m})$ containing the VTA were prepared in ice-cold sucrose substituted ACSF, and allowed to recover at room temperature in ASCF containing the following: $125 \mathrm{~mm} \mathrm{NaCl}, 2.5 \mathrm{~mm} \mathrm{KCl}, 1.25 \mathrm{~mm} \mathrm{NaH}_{2} \mathrm{PO}_{4}$, $25 \mathrm{~mm} \mathrm{NaHCO}_{3}$, $11 \mathrm{~mm}$ glucose, $1 \mathrm{~mm} \mathrm{MgCl}$, and $2 \mathrm{~mm}$ $\mathrm{CaCl}_{2}, \mathrm{pH} 7.4$, for at least $1 \mathrm{~h}$, as described (McCall et al.,
2017). Neurons in the lateral VTA exhibiting appropriate fluorescence were targeted for analysis as this sub-region of the VTA receives prominent input from the NAc that mediates $\mathrm{GABA}_{\mathrm{B}} \mathrm{R}$-dependent feedback (Edwards et al., 2017). Whole-cell data were acquired using a Multiclamp 700A amplifier and pCLAMPv.9.2 software (Molecular Devices, LLC), using recording conditions described in previous publications (McCall et al., 2017). Input/membrane resistance $\left(\mathrm{R}_{\mathrm{M}}\right)$ and apparent capacitance $\left(\mathrm{C}_{\mathrm{M}}\right)$ were determined using a $5 \mathrm{mV} / 10 \mathrm{~ms}$ voltage step, with current responses filtered at $5 \mathrm{~Hz}$. Immediately after establishing whole-cell access, $I_{h}$ conductance was measured using a $200-\mathrm{ms}$ voltage step to $-120 \mathrm{mV}$; the difference in current from beginning to end of the -120$\mathrm{mV}$ step was taken as $\mathrm{I}_{\mathrm{h}}$ amplitude. Subsequently, spontaneous activity was measured in current-clamp mode $(I=0)$ for $1 \mathrm{~min}$. Neurons exhibiting no spontaneous activity were not evaluated. Action potential half-width $\left(\mathrm{AP}_{50}\right)$ was determined by averaging five $\mathrm{AP}_{50}$ values. For rheobase assessments, cells were held in current-clamp mode at $-80 \mathrm{pA}$ to prevent spontaneous activity, and then given 1-s current pulses, beginning at $-100 \mathrm{pA}$ and progressing in 20-pA increments. Rheobase was defined as the minimum current step that evoked one or more action potentials. In chemogenetic experiments, the change in rheobase measured before and after bath application of $\mathrm{CNO}$ application was determined. Somatodendritic holding currents were measured in voltage-clamp mode $\left(V_{\text {hold }}=-60 \mathrm{mV}\right)$ following bath application of CNO (10 $\mu \mathrm{M})$, baclofen $(200 \mu \mathrm{M})$, or quinpirole $(10 \mu \mathrm{M})$. All command potentials factored in a junction potential of $-15 \mathrm{mV}$ predicted using JPCalc software (Molecular Devices, LLC). Series and input resistances were tracked throughout the experiment. If series resistance was unstable or exceeded $20 \mathrm{M} \Omega$, the experiment was excluded from analysis.

\section{Locomotor activity}

Locomotor activity was assessed in open-field activity chambers housed in sound-attenuating cubicles (MedAssociates). Each cubicle was equipped with three 16beam infrared arrays permitting automated measurements of distance traveled (Activity Monitor 5; MedAssociates). Animals were habituated to the testing room for at least $30 \mathrm{~min}$ before testing. Subjects were acclimated over $3 \mathrm{~d}$; on day 1 , animals were handled and placed in the open field for $60 \mathrm{~min}$. On days 2 and 3 , animals were given an intraperitoneal injection of saline and placed in the open field for $60 \mathrm{~min}$. For DREADD experiments, mice were injected with CNO (2 mg/kg, i.p.) $30 \mathrm{~min}$ before either saline, cocaine ( $15 \mathrm{mg} / \mathrm{kg}$, i.p.), or morphine $(10 \mathrm{mg} / \mathrm{kg}$, i.p.) injection on day 4 . Distance traveled during the 60-min period following saline or drug injection was measured; separate cohorts of mice received saline, cocaine and morphine injections. For CRISPR/Cas9 experiments, mice were placed in the open field for $30 \mathrm{~min}$ before injection each day to acclimate to the chamber. Activity was measured on day 3 following saline injection, and again on day 4 following injection of cocaine $(15 \mathrm{mg} /$ $\mathrm{kg}$, i.p.) or morphine (10 mg/kg, i.p.), separate cohorts of mice were used for cocaine and morphine studies. 
Thigmotaxis was quantified by dividing the distance traveled in the periphery by the total distance traveled, as described (Pravetoni and Wickman, 2008). After behavioral testing, the scope and accuracy of viral targeting was assessed by fluorescence microscopy; 225- $\mu$ m horizontal slices of the midbrain were obtained using a vibratome and images were acquired on an Olympus IX-80 microscope using MetaMorph Advanced Acquisition v.7.7.7.0 software (Molecular Devices, LLC). Only data from animals with bilateral viral-driven fluorescence, where the majority of fluorescence was confined to VTA (with minimal spread to the adjacent substantia nigra), were included in the final analysis.

\section{Statistical analysis}

Data are presented throughout as the mean \pm SEM. Statistical analyses were performed using Prism v.9 software (GraphPad Software). All studies included balanced numbers of male and female mice, and data were analyzed first for sex effects. If no sex differences were observed, data from male and female subjects were pooled. If any data point fell outside the range of 2 SDs from the mean, it was excluded as an outlier. Across the entire study, this outlier detection approach led to the removal of one point from the $\mathrm{hM} 4 \mathrm{Di} /$ morphine activity dataset and 1 point from the hM4Di control/morphine activity dataset. Differences were considered significant if $p<0.05$.

\section{Results}

\section{G-protein-dependent inhibition of VTA DA neurons suppresses motor activity}

Motor activation is an unconditioned DA-dependent response in mice to systemic administration of cocaine and morphine (van Rossum et al., 1962; Delfs et al., 1990; Kalivas and Duffy, 1993) that can be recapitulated by direct chemogenetic or optogenetic stimulation of VTA DA neurons (Kim et al., 2012; Tye et al., 2013; Boender et al., 2014; Guo et al., 2014). To test whether inhibitory G-protein-dependent signaling in VTA DA neurons can suppress the locomotor stimulatory effect of systemic cocaine and morphine, we used DATCre $(+)$ mice and a Cre-dependent viral inhibitory chemogenetic approach. Cre-dependent AAV vectors harboring either hM4Di (mCherry) or mCherry control were infused into the VTA of adult male and female DATCre $(+)$ mice to permit selective chemogenetic inhibition of VTA DA neurons (Fig. $1 A$ ).

In acutely isolated midbrain slices from virally treated DATCre $(+)$ mice, bath application of CNO decreased the excitability (increased the rheobase) of hM4Di-expressing, but not mCherry control, DA neurons (Fig. 1B,C). CNO also evoked a somatodendritic inhibitory current $\left(\mathrm{V}_{\text {hold }}=-60 \mathrm{mV}\right)$ reversed by $0.3 \mathrm{~mm} \mathrm{Ba}^{2+}$ in $\mathrm{hM} 4 \mathrm{Di}$ (mCherry)-expressing but not control VTA DA neurons (Fig. 1D,E). Thus, chemogenetic inhibition of VTA DA neurons, like the direct somatodendritic inhibition evoked by $D_{2} R$ and $G A B A_{B} R$ activation, is likely mediated by activation of $\mathrm{G}$-protein-gated inwardly rectifying $\mathrm{K}^{+}$(GIRK/Kir3) channels (Beckstead et al., 2004; Cruz et al., 2004; Labouèbe et al., 2007; Arora et al., 2010).
Consistent with a previous report (Runegaard et al., 2018), chemogenetic inhibition of VTA DA neurons suppressed motor activity evoked by injection of saline, as well as cocaine and morphine (Fig. 1F). These results confirm that VTA DA neurons are key regulators of motor activity in mice and show that activation of inhibitory Gprotein signaling in these neurons can potently suppress baseline activity and the motor-stimulatory effects of cocaine and morphine.

\section{CRISPR/Cas9 ablation of $D_{2} R$ and $G A B A_{B} R$ in VTA DA neurons}

To assess the impact of $D_{2} R$ and $G A B A_{B} R$-dependent signaling pathways in VTA DA neurons on behavioral sensitivity to cocaine and morphine, we developed a DA neuron-specific, viral CRISPR/Cas9 ablation approach. DATCre(+) mice were crossed with a Cre-dependent Cas9GFP line to generate DATCre(+):Cas9GFP $(+)$ mice. $A A V$ vectors harboring gRNAs targeting LacZ (control), $D_{2} R$, or $G A B A_{B} R 1$ were generated and infused into the VTA of male and female DATCre $(+)$ :Cas9GFP $(+)$ mice (Fig. 2A).

To assess the efficacy and selectivity of the viral vectors, somatodendritic currents evoked by bath application of the $D_{2 / 3} R$ agonist quinpirole and the GABA $R$ agonist baclofen were measured in VTA DA neurons five to six weeks after viral infusion. In slices from LacZ gRNAtreated subjects, somatodendritic outward inhibitory currents were reliably evoked by quinpirole and baclofen (Fig. 2B), consistent with previous studies (Beckstead et al., 2004; Cruz et al., 2004; Labouèbe et al., 2007; Arora et al., 2010; McCall et al., 2017). In VTA DA neurons from mice treated with $D_{2} R$ gRNA, quinpirole-induced currents were completely absent (Fig. $2 B, C$ ), while baclofen (applied after quinpirole) evoked normal responses (Fig. $2 B$, $D$ ). Interestingly, a sex difference in the amplitude of quinpirole-induced responses was observed, with currents in VTA DA neurons from female subjects larger than those in males (Fig. 2C). No sex differences were observed in the amplitude of baclofen-induced currents.

In VTA DA neurons from mice treated with $\mathrm{GABA}_{\mathrm{B}} \mathrm{R} 1$ gRNA, somatodendritic responses to baclofen were completely absent (Fig. 2E,F). Responses to quinpirole (applied after baclofen application) were larger than those seen in VTA DA neurons from LacZ-treated controls (Fig. $2 G$ ). As this difference may reflect the impact of prior activation by $G A B A_{B} R$ of a shared effector in control cells, we conducted a separate study where only quinpirole was applied to the slice. In these experiments, quinpirole-induced somatodendritic currents were not significantly different between $\mathrm{GABA}_{\mathrm{B}} \mathrm{R}$-lacking and control VTA DA neurons (Fig. $2 H$ ).

We also examined the impact of $D_{2} R$ and $G A B A_{B} R$ ablation on VTA DA neuron excitability, as measured by spontaneous activity and rheobase. No sex differences were observed with respect to either excitability measure and, as such, data from male and female subjects were pooled to increase the power of the study. Ablation of $D_{2} R$ or $G_{A B A} R$ did not impact spontaneous activity of VTA DA neurons (Fig. 2/) or rheobase (Fig. 2J). Similarly, 

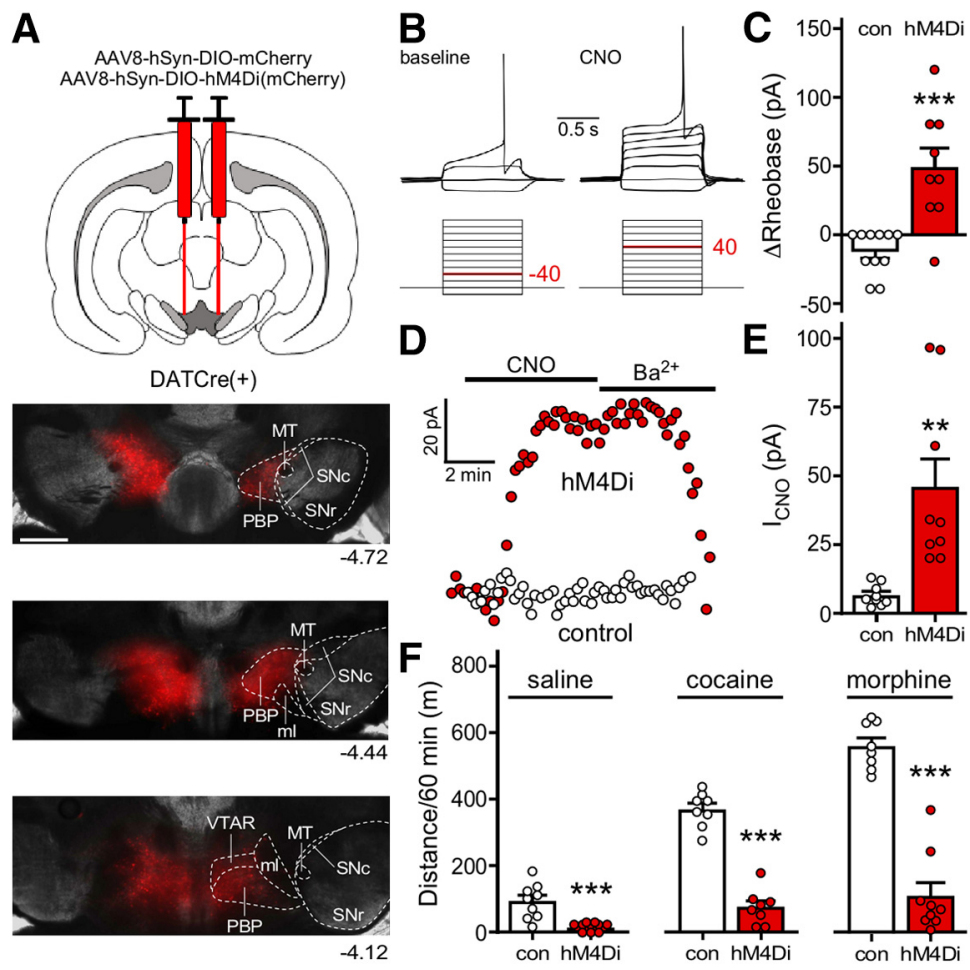

Figure 1. Inhibitory G-protein signaling in VTA DA neurons suppresses baseline and drug-induced motor activity. $\boldsymbol{A}$, Viral targeting in a DATCre $(+)$ mouse treated intra-VTA AAV8-hSyn-DIO-mCherry, with rostro-caudal tiling of panels highlighting viral spread (mCherry fluorescence). ml, medial lemniscus; MT, medial terminal nucleus of the accessory optic tract; PBP, parabrachial pigmented nucleus of the VTA; SNc, substantia nigra pars compacta; SNr, substantia nigra pars reticulata; VTAR, rostral part of the VTA. Scale bar: $500 \mu \mathrm{m}$. B. Example of rheobase measurement in a VTA DA neuron expressing hM4Di, before and after bath perfusion of CNO $(10 \mu \mathrm{m})$. The traces shown were the first to display spiking and were recorded following injection of the current indicated in red below. $\boldsymbol{C}$, Change in rheobase induced by CNO $(10 \mu \mathrm{M})$ in VTA DA neurons from DATCre $(+)$ mice treated with AAV8hSyn-DIO-hM4Di(mCherry) or AAV8-hSyn-DIO-mCherry control $\left(t_{(18)}=4.555 ;{ }^{* * *} p=0.0002\right.$; unpaired Student's $t$ test; $n=9-11 /$ group). $\boldsymbol{D}$, Somatodendritic inhibitory currents $\left(\mathrm{V}_{\text {hold }}=-60 \mathrm{mV}\right)$ evoked by CNO $(10 \mu \mathrm{M})$ in VTA DA neurons from DATCre $(+)$ mice treated with AAV8-hSyn-DIO-hM4Di(mCherry) or AAV8-hSyn-DIO-mCherry control. $\boldsymbol{E}$, Summary of CNO-induced somatodendritic currents in VTA DA neurons from DATCre $(+)$ treated with AAV8-hSyn-DIO-hM4Di(mCherry) or AAV8-hSyn-DIO-mCherry control $\left(t_{(16)}=3.732\right.$; ${ }^{* *} p=0.0018$; unpaired Student's $t$ test; $n=9 /$ group). $\boldsymbol{F}$, Total distance traveled in an open field during the 60-min interval following injection of saline $\left(t_{(16)}=4.385,{ }^{* \star *} p=0.0005\right), 15 \mathrm{mg} / \mathrm{kg}$ cocaine $\left(t_{(14)}=11.20,{ }^{* \star *} p<0.0001\right)$, and $10 \mathrm{mg} / \mathrm{kg} \mathrm{morphine}$ $\left(t_{(15)}=9.401,{ }^{* \star *} p<0.0001\right)$ in DATCre $(+)$ mice treated with intra-VTA AAV8-hSyn-DIO-hM4Di(mCherry) or AAV8-hSyn-DIO-mCherry control ( $n=8-9$ mice/group). CNO (2 mg/kg, i.p.) was administered to all subjects 30 min before saline or drug challenge.

no impact of $D_{2} R$ or $G A B A_{B} R$ ablation was detected on $I_{h}$ current amplitude, cell capacitance, action potential halfwidth, or input resistance (Table 1). Collectively, these data show that we can selectively ablate $G A B A_{B} R$-dependent or $\mathrm{D}_{2} \mathrm{R}$-dependent signaling in VTA DA neurons, and that loss of these signaling pathways does not impact baseline electrophysiological characteristics of VTA DA neurons

\section{Impact of $D_{2} R$ and $G A B A_{B} R$ in VTA DA neurons on baseline and cocaine-induced activity}

We next examined the impact of $D_{2} R$ or $G A B A_{B} R$ ablation on open-field motor activity measured after injection of saline or cocaine. Given the observed sex difference in the strength of $D_{2} R$-dependent signaling in VTA DA neurons, and our prior report of a sex difference in cocaine-induced motor activity in mice (McCall et al., 2017), we analyzed data from male and female subjects separately.
In support of this approach, we found that while male and female LacZ control mice showed no difference in total distance traveled after cocaine injection, the temporal profile of cocaine-induced activity was notably different for male and female subjects (Extended Data Fig. 3-1A), female subjects showed sharper time-to-peak and decay phases relative to male subjects.

In females, we observed main effects of drug and viral treatment, as well as a significant interaction between drug and viral treatment, on total distance traveled in the postinjection interval. $D_{2} R$ or $G A B A_{B} R$ ablation did not impact saline-induced activity in females (Fig. $3 A$, left). Loss of $D_{2} R$, but not $G A B A_{B} R$, yielded enhanced cocaine-induced activity (Fig. $3 A$, right). Although the temporal profile of motor activity during the postinjection interval was qualitatively similar across the groups, loss of $D_{2} R$ and $G_{A B A} R$ in VTA DA neurons correlated with elevated activity levels at all time points following injection (Fig. 3B). Cocaine also enhanced thigmotaxis, as assessed by 

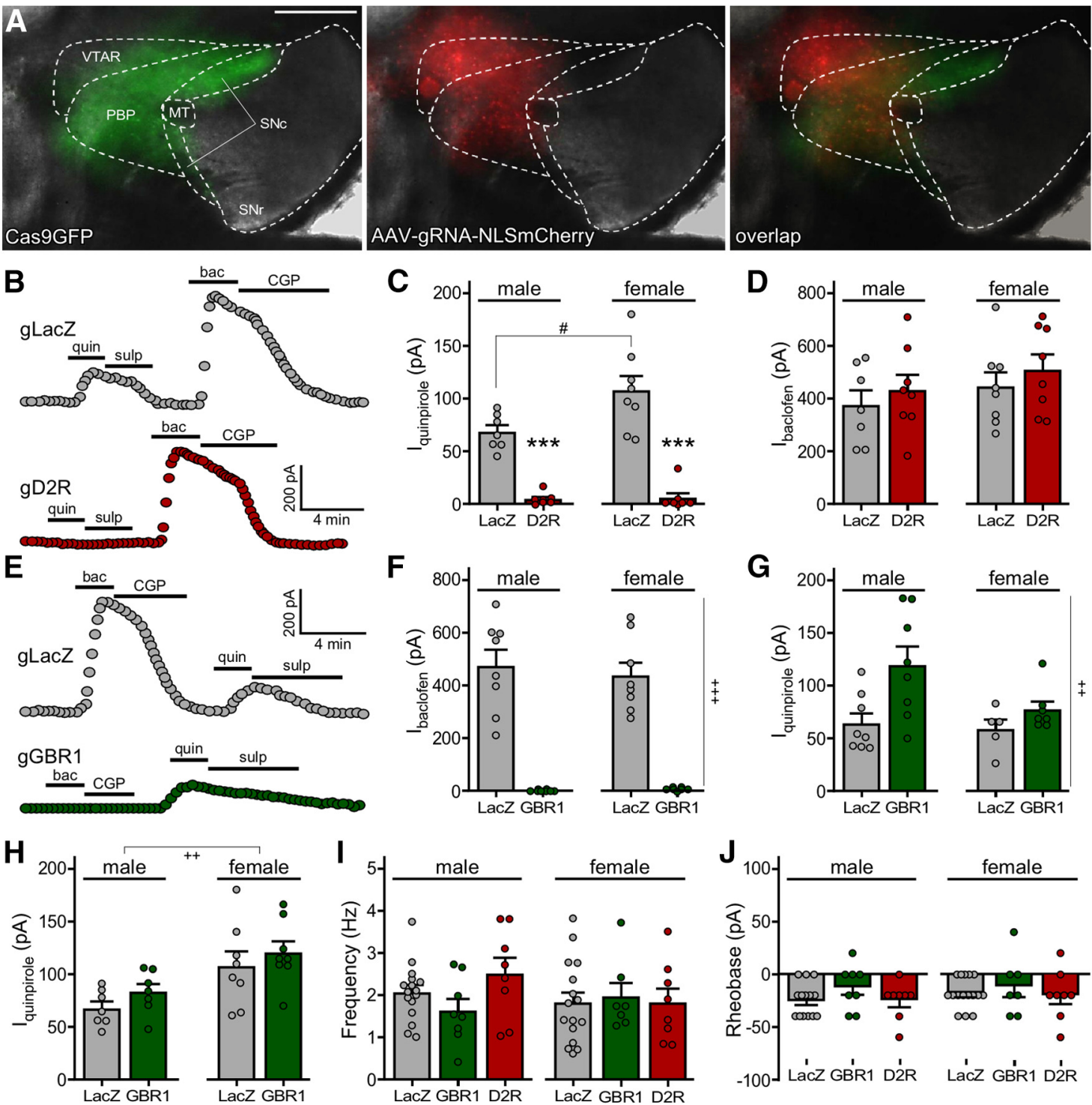

Figure 2. Viral CRISPR/Cas 9 ablation of $G A B A_{B} R$ and $D_{2} R$ in VTA DA neurons. $\boldsymbol{A}$, Viral targeting in a DATCre $(+): C a s 9 G F P(+)$ mouse treated with intra-VTA AAV8-U6-gRNA-hSyn-NLSmCherry; nucleus-localized mCherry fluorescence highlights the anatomic scope of viral targeting, and GFP fluorescence denotes the Cre-dependent expression of Cas9GFP in midbrain DA neurons of the VTA and substantia nigra. MT, medial terminal nucleus of the accessory optic tract; PBP, parabrachial pigmented nucleus of the VTA; SNc, substantia nigra pars compacta; SNr, substantia nigra pars reticulata; VTAR, rostral part of the VTA. Scale bar: $500 \mu \mathrm{m}$. $\boldsymbol{B}$, Somatodendritic inhibitory currents $\left(\mathrm{V}_{\text {hold }}=-60 \mathrm{mV}\right)$ evoked by sequential bath application of quinpirole (quin; $\left.20 \mu \mathrm{m}\right)$ and then baclofen (bac; $200 \mu \mathrm{m}$ ) in VTA DA neurons from DATCre(+):Cas9GFP(+) mice treated with AAV8-U6-gD2R-hSyn-NLSmCherry or AAV8-U6-gLacZ-hSyn-NLSmCherry control. Currents were reversed by the $D_{2 / 3} R$ antagonist sulpiride (sulp; $\left.5 \mu \mathrm{M}\right)$ and $G A B A_{B} R$ antagonist CGP54626 (CGP; $2 \mu \mathrm{M})$. C, Summary of currents evoked by quinpirole (applied first) in VTA DA neurons from DATCre(+): Cas9GFP $(+)$ mice treated with AAV8-U6-gD2R-hSyn-NLSmCherry or AAV8-U6-gLacZ-hSyn-NLSmCherry control. Main effects of $\operatorname{sex}\left(F_{(1,27)}=6.391, p=0.0176\right)$ and viral treatment $\left(F_{(1,27)}=104.6, p<0.0001\right)$ were detected, along with an interaction between sex and viral treatment $\left(F_{(1,27)}=5.590, p=0.0255\right)$; \#p $<0.05$; ${ }^{* \star *} p<0.001$ versus LacZ (within sex). $\boldsymbol{D}$, Summary of currents evoked by baclofen, measured after quinpirole/sulpiride application $(\boldsymbol{C})$, in VTA DA neurons from DATCre $(+)$ :Cas9GFP $(+)$ mice treated with AAV8-U6-gD2R-hSyn-NLSmCherry or AAV8-U6-gLacZ-hSyn-NLSmCherry control. There was no main effect of sex $\left(F_{(1,27)}=1.741\right.$, $p=0.1981)$ or viral treatment $\left(F_{(1,27)}=1.183, p=0.2864\right)$, nor was there an interaction between sex and viral treatment $\left(F_{(1,27)}=\right.$ $0.0047, p=0.9461)$. $E$, Somatodendritic inhibitory currents $\left(V_{\text {hold }}=-60 \mathrm{mV}\right)$ evoked by sequential bath application of baclofen (bac; $200 \mu \mathrm{M}$ ) and then quinpirole (quin; $20 \mu \mathrm{M}$ ) in VTA DA neurons from DATCre(+):Cas9GFP(+) mice treated with AAV8-U6-gGBR1hSyn-NLSmCherry or AAV8-U6-gLacZ-hSyn-NLSmCherry control. Currents were reversed by CGP54626 (CGP; $2 \mu \mathrm{m})$ and sulpiride (sulp; $5 \mu \mathrm{M}$ ). $\boldsymbol{F}$, Summary of currents evoked by baclofen (applied first) in VTA DA neurons from DATCre $(+)$ ):Cas9GFP $(+)$ mice treated with AAV8-U6-gGBR1-hSyn-NLSmCherry or AAV8-U6-gLacZ-hSyn-NLSmCherry control. A main effect of viral treatment was observed $\left(F_{(1,27)}=120.9, p<0.0001\right)$, but there was no main effect of sex $\left(F_{(1,27)}=0.1910, p=0.6655\right)$ or interaction between sex and viral treatment $\left(F_{(1,27)}=0.2216, p=0.6416\right) ;+++p<0.001$ (main effect of viral treatment). $\mathbf{G}$, Summary of currents evoked by quinpirole, measured after baclofen/CGP54626 application $(\boldsymbol{F})$ in VTA DA neurons from DATCre $(+)$ :Cas9GFP $(+)$ mice treated 
continued

with AAV8-U6-gGBR1-hSyn-NLSmCherry or AAV8-U6-gLacZ-hSyn-NLSmCherry control. A main effect of viral treatment was observed $\left(F_{(1,24)}=8.182, p=0.0086\right)$, but there was no main effect of sex $\left(F_{(1,24)}=3.429, p=0.0764\right)$ or interaction between sex and viral treatment $\left(F_{(1,24)}=1.970, p=0.1733\right) ;++p<0.001$ (main effect of viral treatment). $\boldsymbol{H}$, Summary of currents evoked by quinpirole in VTA DA neurons from a separate cohort of DATCre $(+)$ :Cas9GFP $(+)$ mice treated with AAV8-U6-gGBR1-hSyn-NLSmCherry or AAV8-U6-gLacZ-hSyn-NLSmCherry control. A main effect of sex was observed $\left(F_{(1,26)}=13.41, p=0.0011\right)$, but there was no main effect of viral treatment $\left(F_{(1,26)}=1.766, p=0.1954\right)$ or interaction between sex and viral treatment $\left(F_{(1,26)}=0.0129, p=0.9105\right)$; $++p<0.01$ (main effect of sex). $I$, Impact of $D_{2} R$ or $G A B A_{B} R$ ablation on spontaneous activity in VTA DA neurons. No main effect of $\operatorname{sex}\left(F_{(1,56)}=0.7079, p=0.4037\right)$ or viral treatment $\left(F_{(2,56)}=0.6571, p=0.5223\right)$ was detected, nor was there an interaction between sex and viral treatment $\left(F_{(2,56)}=1.276, p=0.2870\right)$. $J$, Impact of $D_{2} R$ or $G A B A_{B} R$ ablation on rheobase in VTA DA neurons. No main effect of $\operatorname{sex}\left(F_{(1,56)}=0.8080, p=0.3725\right)$ or viral treatment $\left(F_{(2,56)}=1.495, p=0.2332\right)$ was detected, nor was there an interaction between sex and viral treatment $\left(F_{(2,56)}=0.1573, p=0.8548\right)$.

calculating the ratio of distance traveled in the field periphery to total distance traveled (Fig. $3 C$ ). There was, however, no impact of $D_{2} R$ or GABA $R$ ablation in VTA DA neurons on thigmotaxis index (Fig. 3C).

In males as in females, we observed main effects of drug and viral treatment, and a significant interaction between drug and viral treatment on total distance traveled. Loss of $D_{2} R$ or $G A B A_{B} R$ did not impact saline-induced activity (Fig. $3 D$, left). In contrast to our observations in females, however, ablation of $D_{2} R$ or $G A B A_{B} R$ in males yielded comparably enhanced cocaine-induced activity over the 60-min postinjection interval (Fig. 3D, right). Interestingly, loss of $D_{2} R$ in males correlated with higher levels of activity seen shortly after cocaine injection (Fig. $3 E$ ), yielding a temporal profile that was qualitatively similar to that observed in females (Extended Data Fig. 3-1B). As was the case with female subjects, thigmotaxis was significantly impacted by drug but not viral treatment (Fig. $3 C)$. Thus, $D_{2} R$-dependent signaling in VTA DA neurons tempers behavioral sensitivity to cocaine in male and female mice, whereas $\mathrm{GABA}_{B} \mathrm{R}$-dependent signaling exerts an influence on behavioral sensitivity to cocaine in male mice only.

\section{Impact of $D_{2} R$ and $G A B A_{B} R$ in VTA DA neurons on baseline and morphine-induced activity}

As we previously reported that the loss of GIRK channel activity in DA neurons in mice correlated with enhance motor stimulation in response to systemic administration of $10 \mathrm{mg} / \mathrm{kg}$, morphine (Kotecki et al., 2015), we next compared the relative contribution of $D_{2} R$ and $G A B A_{B} R$ to this morphine-induced behavior. In female subjects, we observed a main effect of drug on motor activity, but no main effect of viral treatment or interaction between drug and viral treatment. Notably, no significant impact of $D_{2} R$ or $\mathrm{GABA}_{\mathrm{B}} \mathrm{R}$ ablation on morphine-induced activity was observed in females (Fig. $4 A$, right). Although $D_{2} R$ ablation correlated with elevated activity levels at all time points following morphine injection, activity levels were not significantly different from controls (Fig. 4B). Consistent with prior reports (Mickley et al., 1990), we observed a marked increase in thigmotaxis in all subjects after morphine injection, but there was no difference between viral treatment groups (Fig. 4C).

In males, we also observed a main effect of drug, but no main effect of viral treatment or interaction between drug and viral treatment. As was the case in females, loss of either $D_{2} R$ or $G A B A_{B} R$ in males had no significant impact on morphine-induced activity during the 60-min interval (Fig. $4 D$, right) or on the temporal activity profile following morphine injection (Fig. 4E). We also observed a similar increase in thigmotaxis after injection of morphine as seen in females, with no difference between viral treatment groups (Fig. 4F). Thus, neither $D_{2} R$ nor $G A B A_{B} R$ ablation in VTA DA neurons exerts a significant impact on morphine-induced motor activity in mice.

\section{Discussion}

Here, we used a neuron-specific viral CRISPR/Cas9 approach to compare the impact of $D_{2} R$ or $G A B A_{B} R$ ablation in VTA DA neurons on baseline activity and behavioral sensitivity to cocaine and morphine. Loss of $G A B A_{B} R$ or

Table 1: Electrophysiological properties of VTA DA neurons

\begin{tabular}{|c|c|c|c|c|c|c|}
\hline Sex & gRNA & $\mathrm{N} / \mathrm{n}$ & $\mathrm{C}_{\mathrm{M}}(\mathrm{pF})$ & $\mathrm{R}_{\mathrm{M}}(\mathrm{M} \Omega)$ & $I_{h}(p A)$ & $\mathrm{AP}_{50}(\mathrm{~ms})$ \\
\hline \multirow[t]{4}{*}{$\overline{\text { Male }}$} & LacZ & $8 / 15$ & $60 \pm 2$ & $200 \pm 10$ & $313 \pm 49$ & $0.83 \pm 0.04$ \\
\hline & $\mathrm{GABA}_{\mathrm{B}} \mathrm{R} 1$ & $3 / 8$ & $56 \pm 3$ & $194 \pm 11$ & $240 \pm 66$ & $0.92 \pm 0.07$ \\
\hline & $\mathrm{D}_{2} \mathrm{R}$ & $3 / 8$ & $62 \pm 4$ & $207 \pm 34$ & $246 \pm 45$ & $0.92 \pm 0.04$ \\
\hline & & & $\begin{array}{l}F_{(2,28)}=0.8299 \\
p=0.4465\end{array}$ & $\begin{array}{l}F_{(2,28)}=0.1024 \\
p=0.9030\end{array}$ & $\begin{array}{l}F_{(2,28)}=0.6179 \\
p=0.5463\end{array}$ & $\begin{array}{l}F_{(2,28)}=1.154 \\
p=0.3301\end{array}$ \\
\hline \multirow[t]{4}{*}{ Female } & LacZ & $9 / 16$ & $62 \pm 2$ & $186 \pm 11$ & $274 \pm 39$ & $0.85 \pm 0.04$ \\
\hline & $\mathrm{GABA}_{\mathrm{B}} \mathrm{R} 1$ & $3 / 7$ & $60 \pm 4$ & $203 \pm 21$ & $225 \pm 70$ & $0.89 \pm 0.06$ \\
\hline & $D_{2} R$ & $4 / 8$ & $62 \pm 3$ & $174 \pm 22$ & $338 \pm 71$ & $0.99 \pm 0.05$ \\
\hline & & & $\begin{array}{l}F_{(2,28)}=0.2026 \\
p=0.8178\end{array}$ & $\begin{array}{l}F_{(2,28)}=0.6060 \\
p=0.5525\end{array}$ & $\begin{array}{l}F_{(2,28)}=0.7869 \\
p=0.4651\end{array}$ & $\begin{array}{l}F_{(2,28)}=2.431 \\
p=0.1063\end{array}$ \\
\hline
\end{tabular}

Data extracted from whole-cell recordings of VTA DA neurons from male and female DATCre $(+)$ :Cas9GFP(+) mice treated with intra-VTA control (LacZ), D2R, or $\mathrm{GABA}_{\mathrm{B}} \mathrm{R} 1 \mathrm{gRNA}$ vectors. $\mathrm{N} / \mathrm{n}$, number of mice and individual experiments; $\mathrm{C}_{\mathrm{M}}$, apparent capacitance; $\mathrm{R}_{\mathrm{M}}$, input/membrane resistance; $\mathrm{I}_{\mathrm{h}}$, hyperpolarization-activated current; $\mathrm{AP}_{50}$, action-potential half-width. 

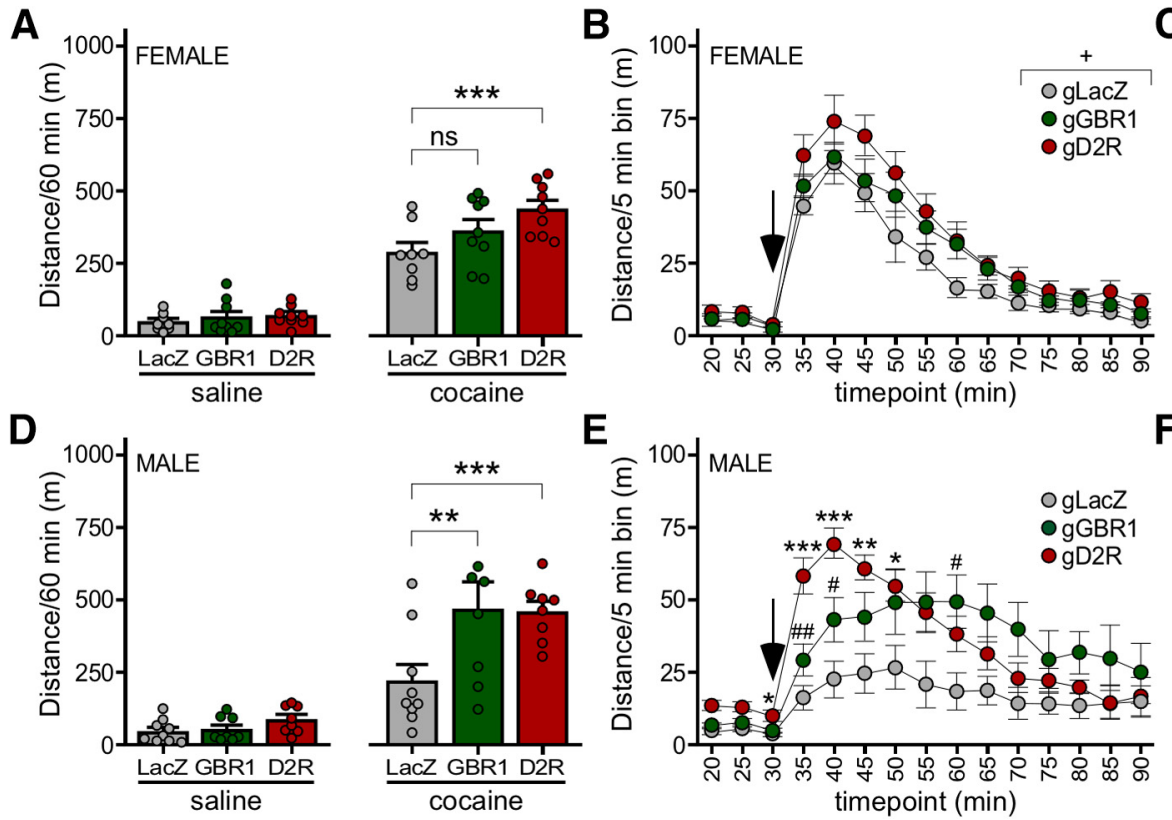

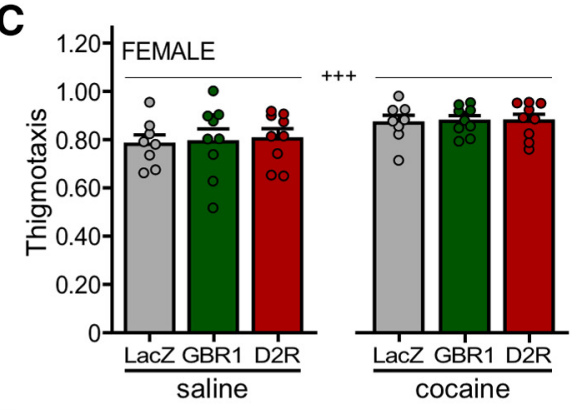

Figure 3. Impact of $\mathrm{GABA}_{\mathrm{B}} \mathrm{R}$ and $\mathrm{D}_{2} \mathrm{R}$ ablation on the motor-stimulatory effect of cocaine. $\boldsymbol{A}$, Total distance traveled during the 60min period after injection of saline (left) or cocaine $(15 \mathrm{mg} / \mathrm{kg}$, i.p., right) in female DATCre $(+)$ :Cas9GFP $(+)$ mice treated with AAV8U6-gGBR1-hSyn-NLSmCherry $(n=9)$, AAV8-U6-gD2R-hSyn-NLSmCherry $(n=9)$, or AAV8-U6-gLacZ-hSyn-NLSmCherry control $(n=8)$. Two-way repeated measures ANOVA revealed main effects of drug $\left(F_{(1,23)}=328.2, p<0.0001\right)$ and viral treatment $\left(F_{(2,23)}=\right.$ 3.778, $p=0.0381)$, and an interaction between drug and viral treatment $\left(F_{(2,23)}=4.600, p=0.0209\right)$; ${ }^{* \star *} p<0.001$; ns, not significant $(p=0.1209)$. $B$, Distance traveled for female subjects before and after cocaine injection (denoted by arrow), evaluated in 5 -min bins. Two-way repeated measures ANOVA revealed a main effect of bin $\left(F_{(3.055,70.26)}=82.89, p<0.0001\right.$; Geisser-Greenhouse correction for sphericity) and viral treatment $\left(F_{(2,23)}=4.613, p=0.0207\right)$, but there was no interaction between bin and viral treatment $\left(F_{(24,276)}=\right.$ $0.9807, p=0.4919) ;+p<0.05$ (main effect of viral treatment). $\boldsymbol{C}$, Thigmotaxis index for female subjects following saline or cocaine injection. Two-way repeated measures ANOVA revealed a main effect of drug $\left(F_{(1,23)}=16.40, p=0.0005\right)$ but not viral treatment $\left(F_{(2,23)}=0.07,351, p=0.9293\right)$, and there was no interaction between drug and viral treatment $\left(F_{(2,23)}=0.03955, p=0.9613\right)$; $+++p<0.001$ (main effect of drug). $\boldsymbol{D}$, Total distance traveled during the 60-min period after injection of saline (left) or cocaine $(15 \mathrm{mg} / \mathrm{kg}$, i.p., right) in male DATCre $(+)$ :Cas9GFP(+) mice treated with AAV8-U6-gGBR1-hSyn-NLSmCherry $(n=8)$, AAV8-U6gD2R-hSyn-NLSmCherry $(n=8)$, or AAV8-U6-gLacZ-hSyn-NLSmCherry control $(n=9)$. Two-way repeated measures ANOVA revealed main effects of drug $\left(F_{(1,22)}=91.27, p=0.0157\right)$ and viral treatment $\left(F_{(2,22)}=4.173, p=0.0291\right)$, and an interaction between drug and viral treatment $\left(F_{(2,22)}=5.050, p=0.0157\right) ;{ }^{* *} p<0.01$ and ${ }^{* * *} p<0.001$. $E$, Distance traveled for male subjects before and after cocaine injection (denoted by arrow), evaluated in 5-min bins. Two-way repeated measures ANOVA revealed a main effect of bin $\left(F_{(3.131,68.88)}=21.10, p<0.0001\right)$ and viral treatment $\left(F_{(2,22)}=4.747, p=0.0193\right)$, and an interaction between bin and viral treatment $\left(F_{(24,264)}=4.743, p<0.0001\right) ;{ }^{*} p<0.05,{ }^{* *} p<0.01,{ }^{* \star *} p<0.001$ (gD2R vs LacZ); \#p $<0.05$ and \#\#p 0.01 (gGBR1 vs LacZ). $\boldsymbol{F}$, Thigmotaxis index for male subjects following saline or cocaine injection. Two-way repeated measures ANOVA revealed a main effect of drug $\left(F_{(1,22)}=21.75, p=0.0001\right)$, but no main effect of viral treatment $\left(F_{(2,22)}=1.534, p=0.2380\right)$ or interaction between drug and viral treatment $\left(F_{(2,22)}=0.9989, p=0.3844\right) ;+++p<0.001$ (main effect of drug).

$D_{2} R$ in VTA DA neurons had no significant impact on baseline activity, paralleling the lack of effect of these manipulations on excitability and other electrophysiological properties of VTA DA neurons. These behavioral findings are consistent with studies involving genetic suppression or ablation of $D_{2} R$ or GABA $R$ in the rodent VTA (de Jong et al., 2015; Edwards et al., 2017). Thus, $D_{2} R$-dependent and $\mathrm{GABA}_{\mathrm{B}} \mathrm{R}$-dependent signaling pathways in VTA DA neurons exert minimal influence on baseline DA neuron excitability. Notably, mice lacking $D_{2} R$ in $D A$ neurons displayed hyperlocomotion (Bello et al., 2011), indicating that $D_{2} R$-dependent signaling in DA neuron populations outside of the VTA may regulate baseline motor activity.

$\mathrm{D}_{2} \mathrm{R}$ ablation in VTA DA neurons potentiated cocaine-induced activity in male and female mice, consistent with studies involving DA neuron-specific ablation of $D_{2} R$ in mice (Bello et al., 2011), and an RNAi-based approach targeting $D_{2} R$ in the rat VTA (de Jong et al., 2015). $\mathrm{GABA}_{\mathrm{B}} \mathrm{R}$ ablation also potentiated cocaine-induced activity, but the influence of this signaling pathway was restricted to males. Enhanced $\mathrm{D}_{2} \mathrm{R}$-dependent signaling in VTA DA neurons from female mice may compensate for the loss of $G A B A_{B} R$ signaling, explaining the weak influence of $G A B A_{B} R$ on cocaine-induced activity in females. Alternatively, there may be reduced GABAergic feedback to VTA DA neurons in females, rendering the loss of $\mathrm{GABA}_{\mathrm{B}} \mathrm{R}$ less effective (Zachry et al., 2021).

Behavioral sensitivity to morphine was unaffected by the loss of $D_{2} R$ and/or GABA $A_{B} R$ in VTA DA neurons, consistent with previous reports (Steketee and Kalivas, 1991; Maldonado et al., 1997; Edwards et al., 2017). The lack of impact of $D_{2} R$ ablation in VTA DA neurons is surprising given that opioids, like cocaine, increase VTA DA levels (Chefer et al., 2009). Cocaine and opioids differ, however, 

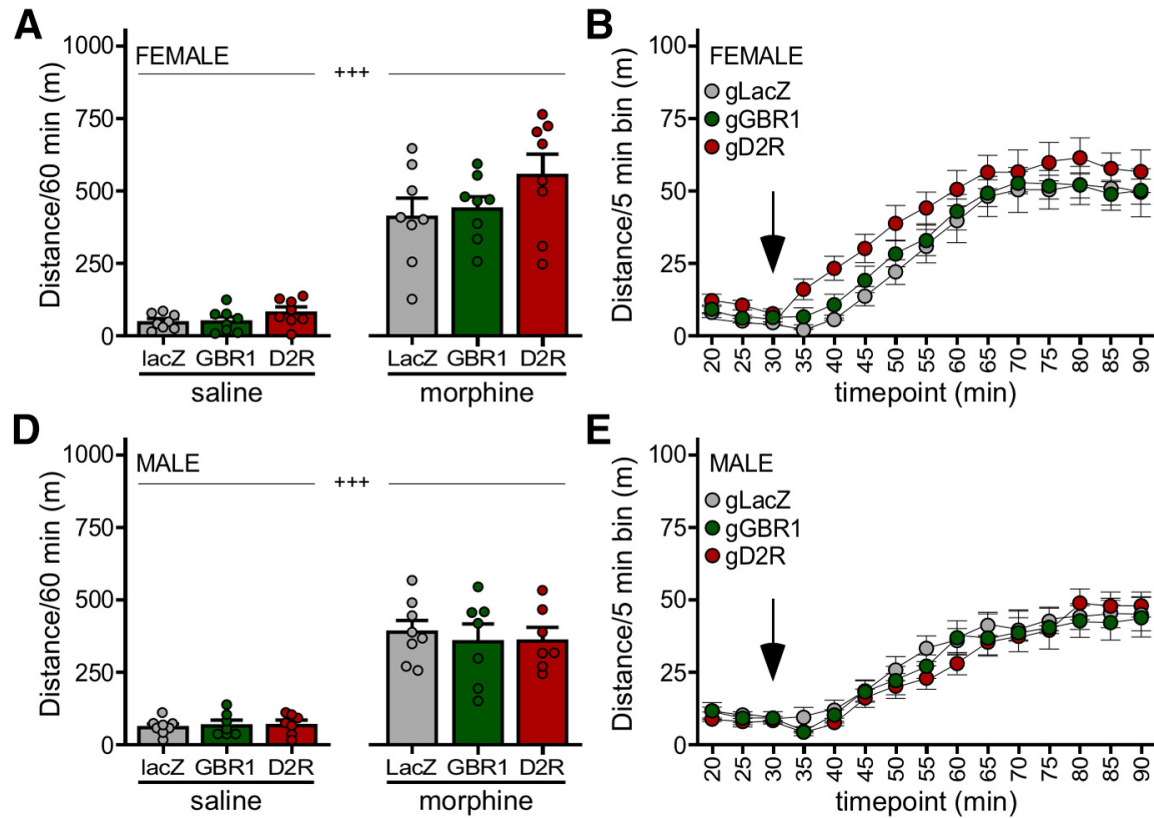

E
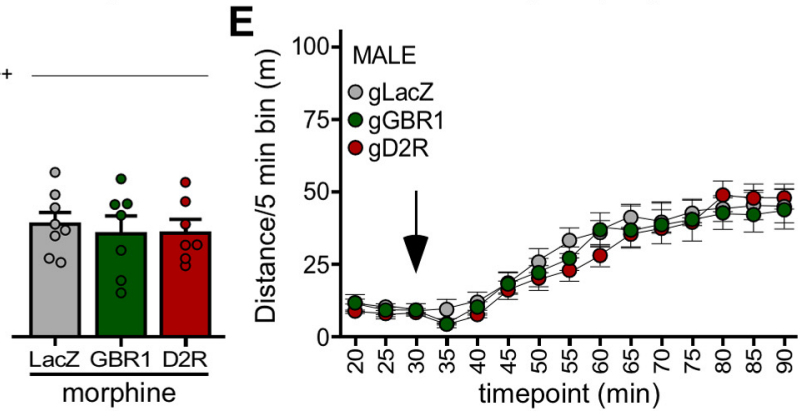

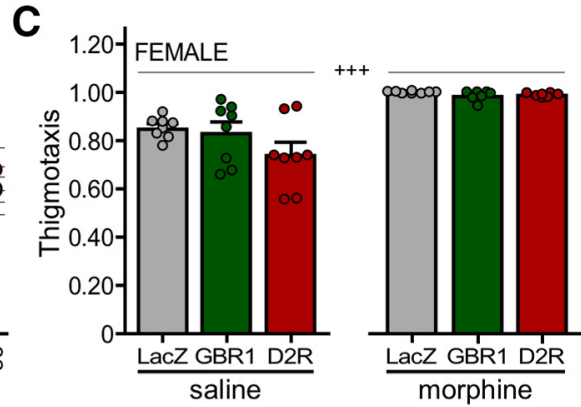

$\mathbf{F}$

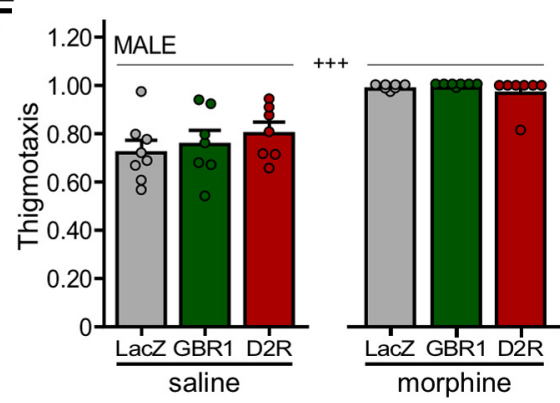

Figure 4. Impact of $G A B A_{B} R$ and $D_{2} R$ ablation on the motor-stimulatory effect of morphine. $\boldsymbol{A}$, Total distance traveled during the 60 -min period after injection of saline (left) or morphine $(10 \mathrm{mg} / \mathrm{kg}$, i.p., right) in female DATCre $(+)$ :Cas9GFP $(+)$ mice treated with AAV8-U6-gGBR1-hSyn-NLSmCherry $(n=8)$, AAV8-U6-gD2R-hSyn-NLSmCherry $(n=8)$, or AAV8-U6-gLacZ-hSyn-NLSmCherry control $(n=8)$. Two-way repeated measures ANOVA revealed a main effect of drug $\left(F_{(1,21)}=185.3, p<0.0001\right)$, but no main effect of viral treatment $\left(F_{(2,21)}=2.145, p=0.1420\right)$ or interaction between drug and viral treatment $\left(F_{(2,21)}=1.183, p=0.3260\right)$; $+++p<0.001$ (main effect of drug). $\boldsymbol{B}$, Distance traveled for female subjects before and after morphine injection (denoted by arrow), evaluated in 5-min bins. Two-way repeated measures ANOVA revealed a main effect of bin $\left(F_{(3.057,67.26)}=97.73, p<0.0001\right)$, but no effect of viral treatment $\left(F_{(2,22)}=1.920, p=0.1704\right)$ or interaction between bin and viral treatment $\left(F_{(24,264)}=0.5380\right.$, $p=0.9640)$. C , Thigmotaxis index for female subjects following saline or morphine injection. Two-way repeated measures ANOVA revealed a main effect of drug $\left(F_{(1,21)}=59.23, p<0.0001\right)$, but no significant difference with viral treatment $\left(F_{(2,21)}=2.462\right.$, $p=0.1095)$, and no interaction between drug and viral treatment $\left(F_{(2,21)}=1.995, p=0.1609\right) ;+++p<0.001$ (main effect of drug). $\boldsymbol{D}$, Total distance traveled during the 60 -min period after injection of saline (left) or morphine (10 mg/kg, i.p., right) in male DATCre(+): Cas9GFP $(+)$ mice treated with AAV8-U6-gGBR1-hSyn-NLSmCherry $(n=7)$, AAV8-U6-gD2R-hSyn-NLSmCherry $(n=7)$, or AAV8-U6gLacZ-hSyn-NLSmCherry control $(n=8)$. Two-way repeated measures ANOVA revealed main effects of drug $\left(F_{(1,19)}=176.1\right.$, $p<0.0001)$, but no main effect of viral treatment $\left(F_{(2,19)}=0.05804, p=0.9438\right)$ or interaction between drug and viral treatment $\left(F_{(2,19)}\right.$ $=0.3193, p=0.7305$ ); $+++p<0.001$ (main effect of drug). $\boldsymbol{E}$. Distance traveled for male subjects before and after morphine injection (denoted by arrow), evaluated in 5-min bins. Two-way repeated measures ANOVA revealed a main effect of bin $\left(F_{(2.264,43.02)}=\right.$ $80.68, p<0.0001)$, but no main effect of viral treatment $\left(F_{(2,19)}=0.1417, p=0.8688\right)$ or interaction between drug and viral treatment $\left(F_{(24,228)}=0.9227, p=0.5711\right)$. $\boldsymbol{F}$, Thigmotaxis index for male subjects following saline or morphine injection. Two-way repeated measures ANOVA revealed a main effect of drug $\left(F_{(1,19)}=68.91, p<0.0001\right)$, but no significant difference with viral treatment $\left(F_{(2,19)}=0.3907, p=0.6819\right)$, and no interaction between drug and viral treatment $\left(F_{(2,19)}=1.195, p=0.3244\right) ;+++p<0.001(\mathrm{main}$ effect of drug).

in their influence on VTA DA neurons. While cocaine hyperpolarizes VTA DA neurons in a $D_{2} R$-dependent manner (Beckstead et al., 2004), opioids increase VTA DA neuron firing by suppressing GABAergic input from local GABA neurons and/or RMTg GABA neurons (Johnson and North, 1992; Jhou et al., 2009; Jalabert et al., 2011), as well as disinhibiting glutamatergic input to VTA DA neurons (Yang et al., 2020). Thus, any inhibitory influence of somatodendritic $D_{2} R$ activation triggered by the opioid-induced rise in VTA DA is likely offset by the excitatory influence of disinhibition.

Since morphine increases NAc DA levels (Spielewoy et al., 2000; Chefer et al., 2003; Vander Weele et al., 2014), and DA neurotransmission in the NAc drives $\mathrm{GABA}_{\mathrm{B}} \mathrm{R}$-dependent feedback to VTA DA neurons (Edwards et al., 2017), it is also surprising that $G A B A_{B} R$ ablation does not impact behavioral sensitivity to morphine. This outcome might reflect differences in the amplitude of the DA increase evoked by cocaine and morphine. Indeed, NAc DA levels in freely moving rats increased more in response to intravenous cocaine than morphine (Pontieri et al., 1995). The spatiotemporal pattern of DA increases in the NAC may also differ for cocaine and morphine. Consistent with this premise, cocaine elicited a more pronounced increase in DA in the NAc shell as compared with core (Aragona et al., 2008, 2009), whereas morphine evoked similar DA increases in NAc core and shell (Vander Weele et al., 2014). Moreover, the morphine-induced increase in NAc DA was relatively transient, a phenomenon potentially linked to a simultaneous increase in NAc GABA levels evoked by morphine (Vander Weele et al., 2014).

The differential apparent engagement of $\mathrm{GABA}_{B} \mathrm{R}$-dependent and $\mathrm{D}_{2} \mathrm{R}$-dependent signaling pathways by cocaine and morphine may also reflect differential molecular 
target location. Morphine can act on opioid receptors in other brain regions to regulate motor activity, bypassing VTA DA neurons. For example, locomotor activity decreased initially following intra-NAc injection of morphine in rats (Costall et al., 1978). In addition, NAc lesions failed to eliminate morphine-induced motor activation, suggesting a potential role of other brain regions in this effect (Stevens et al., 1986). Also, intra-NAc infusion of morphine abolished the motor stimulatory effect of intra-NAc DA, showing that opioid and dopaminergic pathways in the NAc exert competing influence on locomotion (Layer et al., 1991).

The direct inhibitory influence of $G A B A_{B} R$ and $D_{2} R$ activation on VTA DA neurons is mediated primarily by activation of GIRK channels (Brodie and Dunwiddie, 1990; Ackerman et al., 1993; Mercuri et al., 1997; Chen and Pan, 2000; Bunney et al., 2001; Beckstead et al., 2004; Cruz et al., 2004; Ford, 2014), though other effectors are modulated as well (Philippart and Khaliq, 2018; Su et al., 2019). Genetic ablation of Girk2 globally or selectively in DA neurons correlated with increased motor-stimulatory effect of cocaine (Pravetoni and Wickman, 2008; Kotecki et al., 2015; McCall et al., 2017, 2019) and morphine (Kotecki et al., 2015). The contribution of GIRK channels to cocaine-induced activity was further localized to VTA DA neurons (McCall et al., 2019). Given that GIRK channels mediate the $D_{2} R$-dependent and $G A B A_{B} R$-dependent inhibition of VTA DA neurons and that DA neuronspecific loss of GIRK channels enhances the motor-stimulatory effect of cocaine and morphine, the lack of impact of $D_{2} R$ or $G A B A_{B} R$ ablation on morphine-induced activity was unexpected. It is possible that $G A B A_{B} R$-dependent and $D_{2} R$-dependent signaling pathways are functionally redundant and that both need to be eliminated to see an influence on morphine-induced activity. GIRK channels in non-VTA DA neurons, perhaps in the adjacent substantia nigra pars compacta (Koyrakh et al., 2005), may also explain the impact of GIRK channel ablation on morphine.

Females are more susceptible to various facets of addiction (Fattore et al., 2008; Anker and Carroll, 2011; Becker and Koob, 2016), fueling interest in identifying relevant sex differences at molecular and cellular levels. Here, we found multiple sex differences related to inhibitory G-protein signaling in VTA DA neurons. Loss of $\mathrm{GABA}_{B} \mathrm{R}$, for example, had minimal impact on behavioral sensitivity to cocaine in females, but significantly enhanced the motor-stimulatory effect of cocaine in males. $\mathrm{D}_{2} \mathrm{R}$-dependent somatodendritic inhibitory currents were also larger in VTA DA neurons from females. This difference could reflect elevated $D_{2} R$ expression and/or function in VTA DA neurons from females and is predicted to decrease cocaine sensitivity. Indeed, females exhibit elevated $D_{2} R$-dependent signaling at baseline as compared with males (Walker et al., 2006; Zachry et al., 2021).

Cocaine-induced activity was characterized by a more rapid and sharp peak in females as compared with males, which could be explained by a tighter regulation of synaptic DA by DAT in females compared with males (Zachry et al., 2021). $D_{2} R$ ablation in VTA DA neurons in male mice yielded a temporal profile comparable to that seen in female mice. While this suggests that $D_{2} R$-dependent signaling in VTA DA neurons is critical in tempering the early behavioral response to cocaine, the shift in the temporal profile observed in males is somewhat counterintuitive given that somatodendritic $D_{2} R$-dependent signaling is weaker in VTA DA neurons from males. This apparent discrepancy is perhaps explained by sex differences in the influence of presynaptic/terminal $D_{2} R$ (which should also be eliminated by the CRISPR/Cas9 ablation approach) on DA dynamics in the NAc. Presynaptic $D_{2} R$-dependent signaling in VTA DA neurons in males may be stronger than that seen in females. Alternatively, while $D_{2} R$-dependent somatodendritic response amplitudes are larger in VTA DA neurons from female mice, VTA DA neurons in males may be more sensitive to $D_{2} R$-dependent inhibition.

While $D_{2} R$-dependent and $G A B A_{B} R$-dependent signaling pathways in the VTA can suppress behavioral sensitivity to cocaine, psychostimulant exposure can weaken these inhibitory feedback pathways. For example, a transient decrease in $D_{2} R$ influence on VTA DA neuron firing has been reported after repeated cocaine treatment or self-administration (Henry et al., 1989; Ackerman and White, 1990). This adaptation, and corresponding potentiation of cocaine-induced motor activity, was reproduced by repeated quinpirole treatment (Henry et al., 1998). Cocaine self-administration in rats also increased firing rate and burst activity of midbrain DA neurons, paralleled by decreased ability of quinpirole to inhibit DA neuron firing rate (Marinelli et al., 2003). Self-administration of amphetamine in rats reduced the ability of $D_{2} R$ to suppress evoked DA release in the NAc, an effect mediated in part by an RGS2-dependent disruption of $D_{2 / 3} R / G \alpha_{i 2}$ functional coupling (Calipari et al., 2014; Sun et al., 2015). Repeated cocaine in male rats also decreased $G A B A_{B} R /$ G-protein coupling (Kushner and Unterwald, 2001). Finally, cocaine suppressed $\mathrm{GABA}_{B} \mathrm{R}$-dependent somatodendritic signaling in putative VTA DA neurons (Arora et al., 2011), and methamphetamine self-administration suppressed $D_{2} R$-dependent and $G A B A_{B} R$-dependent somatodendritic responses in VTA DA neurons (Sharpe et al., 2014).

Notably, $D_{2} R$ activation appears critical for many of these forms of plasticity, which likely contribute to the hyperexcitability of meso-accumbens DA pathway following psychostimulant exposure (Henry et al., 1998; Francis et al., 2019). The reciprocal relationship between psychostimulants and inhibitory G-protein-dependent feedback pathways in VTA DA neurons may be dependent on age and/or species, or methodological variables. Indeed, repeated methamphetamine injections correlated with enhanced $D_{2} R$-dependent hyperpolarization in young (8-10 d) rats (Amano et al., 2003). In mice, repeated methamphetamine injections suppressed somatodendritic $G A B A_{B} R$-dependent (but not $D_{2} R$ dependent) signaling in VTA DA neurons, but only when methamphetamine was given in novel environment (Munoz et al., 2016).

Our work highlights innate signaling mechanisms that regulate behavioral sensitivity to cocaine. Knowledge of the molecular players and neuron populations regulating behavioral sensitivity to cocaine and other drugs of abuse 
may help in identifying individuals at risk for developing addiction. Further investigation of mechanisms regulating the strength and sensitivity of inhibitory G-protein signaling pathways in VTA DA neurons may suggest opportunities for selective therapeutic interventions tailored to specific drugs of abuse.

\section{References}

Ackerman JM, White FJ (1990) A10 somatodendritic dopamine autoreceptor sensitivity following withdrawal from repeated cocaine treatment. Neurosci Lett 117:181-187.

Ackerman JM, Johansen PA, Clark D, White FJ (1993) Electrophysiological effects of putative autoreceptor-selective dopamine agonists on A10 dopamine neurons. J Pharmacol Exp Ther 265:963-970.

Adell A, Artigas F (2004) The somatodendritic release of dopamine in the ventral tegmental area and its regulation by afferent transmitter systems. Neurosci Biobehav Rev 28:415-431.

Adrover MF, Shin JH, Alvarez VA (2014) Glutamate and dopamine transmission from midbrain dopamine neurons share similar release properties but are differentially affected by cocaine. $\mathrm{J}$ Neurosci 34:3183-3192.

Amano T, Matsubayashi H, Seki T, Sasa M, Sakai N (2003) Repeated administration of methamphetamine causes hypersensitivity of D2 receptor in rat ventral tegmental area. Neurosci Lett 347:89-92.

Anker JJ, Carroll ME (2011) Females are more vulnerable to drug abuse than males: evidence from preclinical studies and the role of ovarian hormones. Curr Top Behav Neurosci 8:73-96.

Aragona BJ, Cleaveland NA, Stuber GD, Day JJ, Carelli RM, Wightman RM (2008) Preferential enhancement of dopamine transmission within the nucleus accumbens shell by cocaine is attributable to a direct increase in phasic dopamine release events. J Neurosci 28:8821-8831.

Aragona BJ, Day JJ, Roitman MF, Cleaveland NA, Wightman RM, Carelli RM (2009) Regional specificity in the real-time development of phasic dopamine transmission patterns during acquisition of a cue-cocaine association in rats. Eur J Neurosci 30:1889-1899.

Arora D, Haluk DM, Kourrich S, Pravetoni M, Fernández-Alacid L, Nicolau JC, Luján R, Wickman K (2010) Altered neurotransmission in the mesolimbic reward system of Girk mice. J Neurochem 114:1487-1497.

Arora D, Hearing M, Haluk DM, Mirkovic K, Fajardo-Serrano A, Wessendorf MW, Watanabe M, Luján R, Wickman K (2011) Acute cocaine exposure weakens $\mathrm{GABA}(\mathrm{B})$ receptor-dependent G-protein-gated inwardly rectifying $\mathrm{K}+$ signaling in dopamine neurons of the ventral tegmental area. J Neurosci 31:12251-12257.

Backes EN, Hemby SE (2008) Contribution of ventral tegmental GABA receptors to cocaine self-administration in rats. Neurochem Res 33:459-467.

Beart PM, McDonald D, Gundlach AL (1979) Mesolimbic dopaminergic neurones and somatodendritic mechanisms. Neurosci Lett 15:165-170.

Becker JB, Koob GF (2016) Sex differences in animal models: focus on addiction. Pharmacol Rev 68:242-263.

Beckstead MJ, Grandy DK, Wickman K, Williams JT (2004) Vesicular dopamine release elicits an inhibitory postsynaptic current in midbrain dopamine neurons. Neuron 42:939-946.

Bello EP, Mateo Y, Gelman DM, Noaín D, Shin JH, Low MJ, Alvarez VA, Lovinger DM, Rubinstein M (2011) Cocaine supersensitivity and enhanced motivation for reward in mice lacking dopamine D2 autoreceptors. Nat Neurosci 14:1033-1038.

Bernosky-Smith KA, Qiu YY, Feja M, Lee YB, Loughlin B, Li JX, Bass CE (2018) Ventral tegmental area D2 receptor knockdown enhances choice impulsivity in a delay-discounting task in rats. Behav Brain Res 341:129-134.

Boender AJ, de Jong JW, Boekhoudt L, Luijendijk MC, van der Plasse G, Adan RA (2014) Combined use of the canine adenovirus-2 and DREADD-technology to activate specific neural pathways in vivo. PLoS One 9:e95392.

Bradberry CW, Roth RH (1989) Cocaine increases extracellular dopamine in rat nucleus accumbens and ventral tegmental area as shown by in vivo microdialysis. Neurosci Lett 103:97-102.

Brebner K, Phelan R, Roberts DC (2000) Intra-VTA baclofen attenuates cocaine self-administration on a progressive ratio schedule of reinforcement. Pharmacol Biochem Behav 66:857-862.

Brodie MS, Dunwiddie TV (1990) Cocaine effects in the ventral tegmental area: evidence for an indirect dopaminergic mechanism of action. Naunyn Schmiedebergs Arch Pharmacol 342:660-665.

Bunney EB, Appel SB, Brodie MS (2001) Electrophysiological effects of cocaethylene, cocaine, and ethanol on dopaminergic neurons of the ventral tegmental area. J Pharmacol Exp Ther 297:696-703.

Calipari ES, Sun H, Eldeeb K, Luessen DJ, Feng X, Howlett AC, Jones SR, Chen R (2014) Amphetamine self-administration attenuates dopamine D2 autoreceptor function. Neuropsychopharmacology 39:1833-1842.

Chefer VI, Kieffer BL, Shippenberg TS (2003) Basal and morphineevoked dopaminergic neurotransmission in the nucleus accumbens of MOR- and DOR-knockout mice. Eur J Neurosci 18:19151922.

Chefer VI, Denoroy L, Zapata A, Shippenberg TS (2009) Mu opioid receptor modulation of somatodendritic dopamine overflow: GABAergic and glutamatergic mechanisms. Eur $\mathrm{J}$ Neurosci 30:272-278.

Chen NH, Reith ME (1994) Autoregulation and monoamine interactions in the ventral tegmental area in the absence and presence of cocaine: a microdialysis study in freely moving rats. J Pharmacol Exp Ther 271:1597-1610.

Chen NN, Pan WH (2000) Regulatory effects of D2 receptors in the ventral tegmental area on the mesocorticolimbic dopaminergic pathway. J Neurochem 74:2576-2582.

Chen R, McIntosh S, Hemby SE, Sun H, Sexton T, Martin TJ, Childers SR (2018) High and low doses of cocaine intake are differentially regulated by dopamine D2 receptors in the ventral tegmental area and the nucleus accumbens. Neurosci Lett 671:133-139.

Chen SH, Haam J, Walker M, Scappini E, Naughton J, Martin NP (2019) Production of viral constructs for neuroanatomy, calcium imaging, and optogenetics. Curr Protoc Neurosci 87:e66.

Chen SY, Burger RI, Reith ME (1996) Extracellular dopamine in the rat ventral tegmental area and nucleus accumbens following ventral tegmental infusion of cocaine. Brain Res 729:294-296.

Costall B, Fortune DH, Naylor RJ (1978) The induction of catalepsy and hyperactivity by morphine administered directly into the nucleus accumbens of rats. Eur J Pharmacol 49:49-64.

Cruz HG, Ivanova T, Lunn M-L, Stoffel M, Slesinger PA, Lüscher C (2004) Bi-directional effects of $\mathrm{GABA}(\mathrm{B})$ receptor agonists on the mesolimbic dopamine system. Nat Neurosci 7:153-159.

de Jong JW, Roelofs TJ, Mol FM, Hillen AE, Meijboom KE, Luijendijk MC, van der Eerden HA, Garner KM, Vanderschuren LJ, Adan RA (2015) Reducing ventral tegmental dopamine D2 receptor expression selectively boosts incentive motivation. Neuropsychopharmacology 40:2085-2095.

Delfs JM, Schreiber L, Kelley AE (1990) Microinjection of cocaine into the nucleus accumbens elicits locomotor activation in the rat. $\mathrm{J}$ Neurosci 10:303-310.

Di Chiara G, Imperato A (1988) Drugs abused by humans preferentially increase synaptic dopamine concentrations in the mesolimbic system of freely moving rats. Proc Natl Acad Sci USA 85:52745278.

Edwards NJ, Tejeda HA, Pignatelli M, Zhang S, McDevitt RA, Wu J, Bass CE, Bettler B, Morales M, Bonci A (2017) Circuit specificity in the inhibitory architecture of the VTA regulates cocaine-induced behavior. Nat Neurosci 20:438-448.

Einhorn LC, Johansen PA, White FJ (1988) Electrophysiological effects of cocaine in the mesoaccumbens dopamine system: studies in the ventral tegmental area. J Neurosci 8:100-112. 
Fattore L, Altea S, Fratta W (2008) Sex differences in drug addiction: a review of animal and human studies. Womens Health (Lond) 4:51-65.

Ford CP (2014) The role of D2-autoreceptors in regulating dopamine neuron activity and transmission. Neuroscience 282:13-22.

Francis TC, Gantz SC, Moussawi K, Bonci A (2019) Synaptic and intrinsic plasticity in the ventral tegmental area after chronic cocaine. Curr Opin Neurobiol 54:66-72.

Groves PM, Wilson CJ, Young SJ, Rebec GV (1975) Self-inhibition by dopaminergic neurons. Science 190:522-528.

Guo S, Chen S, Zhang Q, Wang Y, Xu K, Zheng X (2014) Optogenetic activation of the excitatory neurons expressing CaMKIl $\alpha$ in the ventral tegmental area upregulates the locomotor activity of free behaving rats. Biomed Res Int 2014:687469.

Henry DJ, Greene MA, White FJ (1989) Electrophysiological effects of cocaine in the mesoaccumbens dopamine system: repeated administration. J Pharmacol Exp Ther 251:833-839.

Henry DJ, Hu XT, White FJ (1998) Adaptations in the mesoaccumbens dopamine system resulting from repeated administration of dopamine D1 and D2 receptor-selective agonists: relevance to cocaine sensitization. Psychopharmacology (Berl) 140:233-242.

Holroyd KB, Adrover MF, Fuino RL, Bock R, Kaplan AR, Gremel CM, Rubinstein M, Alvarez VA (2015) Loss of feedback inhibition via D2 autoreceptors enhances acquisition of cocaine taking and reactivity to drug-paired cues. Neuropsychopharmacology 40:14951509.

Hyman SE, Malenka RC, Nestler EJ (2006) Neural mechanisms of addiction: the role of reward-related learning and memory. Annu Rev Neurosci 29:565-598.

Iravani MM, Muscat R, Kruk ZL (1996) Comparison of somatodendritic and axon terminal dopamine release in the ventral tegmental area and the nucleus accumbens. Neuroscience 70:1025-1037.

Jalabert M, Bourdy R, Courtin J, Veinante P, Manzoni OJ, Barrot M, Georges F (2011) Neuronal circuits underlying acute morphine action on dopamine neurons. Proc Natl Acad Sci USA 108:1644616450.

Jhou TC, Fields HL, Baxter MG, Saper CB, Holland PC (2009) The rostromedial tegmental nucleus (RMTg), a GABAergic afferent to midbrain dopamine neurons, encodes aversive stimuli and inhibits motor responses. Neuron 61:786-800.

Johnson SW, North RA (1992) Opioids excite dopamine neurons by hyperpolarization of local interneurons. J Neurosci 12:483-488.

Juarez B, Han MH (2016) Diversity of dopaminergic neural circuits in response to drug exposure. Neuropsychopharmacology 41:24242446.

Kalivas PW, Duffy P (1993) Time course of extracellular dopamine and behavioral sensitization to cocaine. I. Dopamine axon terminals. J Neurosci 13:266-275.

Kalivas PW, Duffy P, Eberhardt H (1990) Modulation of A10 dopamine neurons by gamma-aminobutyric acid agonists. J Pharmacol Exp Ther 253:858-866.

Kim KM, Baratta MV, Yang A, Lee D, Boyden ES, Fiorillo CD (2012) Optogenetic mimicry of the transient activation of dopamine neurons by natural reward is sufficient for operant reinforcement. PLoS One 7:e33612.

Kita JM, Kile BM, Parker LE, Wightman RM (2009) In vivo measurement of somatodendritic release of dopamine in the ventral tegmental area. Synapse 63:951-960.

Kotecki L, Hearing M, McCall NM, Marron Fernandez de Velasco E, Pravetoni M, Arora D, Victoria NC, Munoz MB, Xia Z, Slesinger PA, Weaver CD, Wickman K (2015) GIRK channels modulate opioid-induced motor activity in a cell type- and subunit-dependent manner. J Neurosci 35:7131-7142.

Koulchitsky S, Delairesse C, Beeken T, Monteforte A, Dethier J, Quertemont E, Findeisen R, Bullinger E, Seutin V (2016) Activation of D2 autoreceptors alters cocaine-induced locomotion and slows down local field oscillations in the rat ventral tegmental area. Neuropharmacology 108:120-127.
Koyrakh L, Luján R, Colón J, Karschin C, Kurachi Y, Karschin A, Wickman K (2005) Molecular and cellular diversity of neuronal Gprotein-gated potassium channels. J Neurosci 25:11468-11478.

Kushner SA, Unterwald EM (2001) Chronic cocaine administration decreases the functional coupling of $\mathrm{GABA}(\mathrm{B})$ receptors in the rat ventral tegmental area as measured by baclofen-stimulated 35SGTPgammaS binding. Life Sci 69:1093-1102.

Labouèbe $G$, Lomazzi $M$, Cruz HG, Creton $C$, Luján R, Li $M$, Yanagawa Y, Obata K, Watanabe M, Wickman K, Boyer SB, Slesinger PA, Lüscher C (2007) RGS2 modulates coupling between GABAB receptors and GIRK channels in dopamine neurons of the ventral tegmental area. Nat Neurosci 10:1559-1568.

Lammel S, Lim BK, Malenka RC (2014) Reward and aversion in a heterogeneous midbrain dopamine system. Neuropharmacology 76:351-359.

Layer RT, Uretsky NJ, Wallace LJ (1991) Effects of morphine in the nucleus accumbens on stimulant-induced locomotion. Pharmacol Biochem Behav 40:21-26.

Leite-Morris KA, Fukudome EY, Kaplan GB (2002) Opiate-induced motor stimulation is regulated by gamma-aminobutyric acid type $B$ receptors found in the ventral tegmental area in mice. Neurosci Lett 317:119-122.

Leite-Morris KA, Fukudome EY, Shoeb MH, Kaplan GB (2004) GABA (B) receptor activation in the ventral tegmental area inhibits the acquisition and expression of opiate-induced motor sensitization. $J$ Pharmacol Exp Ther 308:667-678.

Lüscher C (2016) The emergence of a circuit model for addiction. Annu Rev Neurosci 39:257-276.

Lüscher C, Ungless MA (2006) The mechanistic classification of addictive drugs. PLoS Med 3:e437. [

Maldonado R, Saiardi A, Valverde O, Samad TA, Roques BP, Borrelli $E$ (1997) Absence of opiate rewarding effects in mice lacking dopamine D2 receptors. Nature 388:586-589.

Marinelli M, Cooper DC, Baker LK, White FJ (2003) Impulse activity of midbrain dopamine neurons modulates drug-seeking behavior. Psychopharmacology (Berl) 168:84-98.

Martin TA, Smith HR, Luessen DJ, Chen R, Porrino LJ (2020) Functional brain activity is globally elevated by dopamine D2 receptor knockdown in the ventral tegmental area. Brain Res 1727:146552.

McCall NM, Kotecki L, Dominguez-Lopez S, Marron Fernandez de Velasco E, Carlblom N, Sharpe AL, Beckstead MJ, Wickman K (2017) Selective ablation of GIRK channels in dopamine neurons alters behavioral effects of cocaine in mice. Neuropsychopharmacology 42:707-715.

McCall NM, Marron Fernandez de Velasco E, Wickman K (2019) GIRK channel activity in dopamine neurons of the ventral tegmental area bidirectionally regulates behavioral sensitivity to cocaine. $\mathrm{J}$ Neurosci 39:3600-3610.

Menegas W, Bergan JF, Ogawa SK, Isogai Y, Umadevi Venkataraju K, Osten P, Uchida N, Watabe-Uchida M (2015) Dopamine neurons projecting to the posterior striatum form an anatomically distinct subclass. Elife 4:e10032.

Mercuri NB, Saiardi A, Bonci A, Picetti R, Calabresi P, Bernardi G, Borrelli E (1997) Loss of autoreceptor function in dopaminergic neurons from dopamine D2 receptor deficient mice. Neuroscience 79:323-327.

Mickley GA, Mulvihill MA, Postler MA (1990) Brain mu and delta opioid receptors mediate different locomotor hyperactivity responses of the C57BL/6J mouse. Psychopharmacology (Berl) 101:332-337.

Munoz MB, Padgett CL, Rifkin R, Terunuma M, Wickman K, Contet C, Moss SJ, Slesinger PA (2016) A role for the GIRK3 subunit in methamphetamine-induced attenuation of GABAB receptor-activated GIRK currents in VTA dopamine neurons. J Neurosci 36:3106-3114.

Narayanan S, Wallace L, Uretsky N (1996) Spontaneous and drugstimulated locomotor activity after the administration of pertussis toxin into the ventral tegmental area. J Psychiatry Neurosci 21:172-180. 
Philippart F, Khaliq ZM (2018) Gi/o protein-coupled receptors in dopamine neurons inhibit the sodium leak channel NALCN. Elife 7: e40984.

Pignatelli M, Bonci A (2018) Spiraling connectivity of NAc-VTA circuitry. Neuron 97:261-262.

Platt RJ, Chen S, Zhou Y, Yim MJ, Swiech L, Kempton HR, Dahlman JE, Parnas O, Eisenhaure TM, Jovanovic M, Graham DB, Jhunjhunwala S, Heidenreich M, Xavier RJ, Langer R, Anderson DG, Hacohen N, Regev A, Feng G, Sharp PA, et al. (2014) CRISPR-Cas9 knockin mice for genome editing and cancer modeling. Cell 159:440-455.

Pontieri FE, Tanda G, Di Chiara G (1995) Intravenous cocaine, morphine, and amphetamine preferentially increase extracellular dopamine in the "shell" as compared with the "core" of the rat nucleus accumbens. Proc Natl Acad Sci USA 92:12304-12308.

Pravetoni M, Wickman K (2008) Behavioral characterization of mice lacking GIRK/Kir3 channel subunits. Genes Brain Behav 7:523531.

Rahman S, McBride WJ (2000) Feedback control of mesolimbic somatodendritic dopamine release in rat brain. I Neurochem 74:684-692.

Rahman S, McBride WJ (2001) D1-D2 dopamine receptor interaction within the nucleus accumbens mediates long-loop negative feedback to the ventral tegmental area (VTA). J Neurochem 77:12481255.

Runegaard AH, Sørensen AT, Fitzpatrick CM, Jørgensen SH, Petersen AV, Hansen NW, Weikop P, Andreasen JT, Mikkelsen JD, Perrier JF, Woldbye D, Rickhag M, Wortwein G, Gether U (2018) Locomotor- and reward-enhancing effects of cocaine are differentially regulated by chemogenetic stimulation of Gi-signaling in dopaminergic neurons. eNeuro 5:ENEURO.0345-17.2018.

Schultz W (2016) Dopamine reward prediction-error signalling: a two-component response. Nat Rev Neurosci 17:183-195.

Sharpe AL, Varela E, Bettinger L, Beckstead MJ (2014) Methamphetamine self-administration in mice decreases GIRK channel-mediated currents in midbrain dopamine neurons. Int J Neuropsychopharmacol 18:pyu073-pyu073.

Spielewoy C, Gonon F, Roubert C, Fauchey V, Jaber M, Caron MG, Roques BP, Hamon M, Betancur C, Maldonado R, Giros B (2000) Increased rewarding properties of morphine in dopamine-transporter knockout mice. Eur J Neurosci 12:1827-1837.

Steketee JD, Kalivas PW (1990) Sensitization to cocaine produced by injection of pertussis toxin into the A10 dopamine region. NIDA Res Monogr 105:545-546.

Steketee JD, Kalivas PW (1991) Sensitization to psychostimulants and stress after injection of pertussis toxin into the A10 dopamine region. J Pharmacol Exp Ther 259:916-924.
Stevens KE, Mickley GA, McDermott LJ (1986) Brain areas involved in production of morphine-induced locomotor hyperactivity of the C57B1/6J mouse. Pharmacol Biochem Behav 24:1739-1747.

Su M, Li L, Wang J, Sun H, Zhang L, Zhao C, Xie Y, Gamper N, Du X, Zhang H (2019) Kv7.4 channel contribute to projection-specific auto-inhibition of dopamine neurons in the ventral tegmental area. Front Cell Neurosci 13:557.

Sun H, Calipari ES, Beveridge TJ, Jones SR, Chen R (2015) The brain gene expression profile of dopamine D2/D3 receptors and associated signaling proteins following amphetamine self-administration. Neuroscience 307:253-261.

Tanabe LM, Suto N, Creekmore E, Steinmiller CL, Vezina P (2004) Blockade of D2 dopamine receptors in the VTA induces a longlasting enhancement of the locomotor activating effects of amphetamine. Behav Pharmacol 15:387-395.

Tye KM, Mirzabekov JJ, Warden MR, Ferenczi EA, Tsai HC, Finkelstein J, Kim SY, Adhikari A, Thompson KR, Andalman AS, Gunaydin LA, Witten IB, Deisseroth K (2013) Dopamine neurons modulate neural encoding and expression of depression-related behaviour. Nature 493:537-541.

van Rossum J, van der SJ, Hurkmans JA (1962) Mechanism of action of cocaine and amphetamine in the brain. Experientia 18:229-231.

Vander Weele CM, Porter-Stransky KA, Mabrouk OS, Lovic V, Singer BF, Kennedy RT, Aragona BJ (2014) Rapid dopamine transmission within the nucleus accumbens: dramatic difference between morphine and oxycodone delivery. Eur J Neurosci 40:3041-3054.

Volkow ND, Morales M (2015) The brain on drugs: from reward to addiction. Cell 162:712-725.

Walker QD, Ray R, Kuhn CM (2006) Sex differences in neurochemical effects of dopaminergic drugs in rat striatum. Neuropsychopharmacology 31:1193-1202.

Watabe-Uchida M, Zhu L, Ogawa SK, Vamanrao A, Uchida N (2012) Whole-brain mapping of direct inputs to midbrain dopamine neurons. Neuron 74:858-873.

Xi ZX, Stein EA (1999) Baclofen inhibits heroin self-administration behavior and mesolimbic dopamine release. J Pharmacol Exp Ther 290:1369-1374.

Xue Y, Steketee JD, Rebec GV, Sun W (2011) Activation of D2-like receptors in rat ventral tegmental area inhibits cocaine-reinstated drug-seeking behavior. Eur J Neurosci 33:1291-1298.

Yang L, Chen M, Ma Q, Sheng H, Cui D, Shao D, Lai B, Zheng P (2020) Morphine selectively disinhibits glutamatergic input from mPFC onto dopamine neurons of VTA, inducing reward. Neuropharmacology 176:108217.

Zachry JE, Nolan SO, Brady LJ, Kelly SJ, Siciliano CA, Calipari ES (2021) Sex differences in dopamine release regulation in the striatum. Neuropsychopharmacology 46:491-499. 